\title{
Vocational Teachers' Perception of the Effects on Increasing Recruitment Benefit of the 12-Year Compulsory Education's Pioneer Program
}

\author{
Tsai-Ku Liao, Hui-Yi Pai, Yi-Chen Chang, and Chin-Wen Liao
}

\begin{abstract}
The objective of this study is to explore the perceptions of vocational teachers in senior high schools, with teachers' different backgrounds as variables, regarding the effects of the preparatory measures of the 12-year fundamental education program on increasing student recruitment. This study constructed the questionnaire as the research tool. Upon an initial review by scholars and experts, trial test questionnaires were issued to vocational teachers affiliated with five schools in central Taiwan. After the trial test questionnaires were recovered, statistic analysis were performed to screen for validity and to eliminate questions with low correlations. Formal questionnaires were then constructed and issued to vocational teachers at 25 schools selected with the stratified random sampling method from the varied populations; 568 out of the 691 issued questionnaires were recovered, for an effective recovery rate of $82.20 \%$. SPSS20.0 software was used for data analysis, with such statistical methods as frequency distribution, percentage, means, standard deviation, t-test, One Way ANOVA and Pearson Product-Moment Correlation.
\end{abstract}

Index Terms-12-year fundamental education, student recruitment, vocational teachers.

\section{INTRODUCTION}

The Department of Statistics (DOS) of the Ministry of Education (MOE) forecast the following projection relating to the number of senior secondary education students: the number of the graduates of junior high schools will fall from 316,630 to 197,002 from the 2011 school year to the 2021 year, meaning an annual reduction of around 10 thousand [1]; the number of high school freshmen in 2021 will be less than 200 thousand, meaning a shortage of over 18 thousand in general and vocational high schools if the current approved recruitment of 38 thousand remains unchanged [2]. Due to the impact caused by the low birth rate as well as aging in the demographic structure, the surging number of children with foreign-born parents and changes in the educational environment, people from various fields are expecting educational reform to thoroughly resolve the current educational dilemma and improve the quality of the nation's manpower, which validates the need for extending fundamental education [3].

Although plans to extend fundamental education have been on-going since 1983, it was not until New Year's Day,

Manuscript received March 8, 2014; revised May 10, 2014.

The authors are with the Department of Industrial Education and Technology at National Changhua University of Education (NCUE), Taiwan (e-mail: tsaikuliao@gmail.com,_yi2323222@yahoo.com.tw, yd3174@gmail.com, tcwliao@cc.ncue.edu.tw).
2011 that a formal announcement was made to launch the 12-year program of fundamental education [3]. Preparatory measures for such a launch have been extensive, covering: "policy of general and vocational high schools settling in communities" in 2001; "subsidy plan for quality general and vocational high schools" and "tuition reimbursement for private general and vocational high schools - minimizing the tuition gap between public and private schools" in 2007; "homogenization implementation plan of general and vocational high schools' adaptive learning community educational resources" in 2009, etc.; realizing educational resource- sharing through horizontal integration; vertical linkage among general and vocational high schools; achieving quality general and vocational high schools to further improve education and satisfy students' educational requirements; and putting into practice the target of enrolling in nearby schools, which supports the homogenization of public and private schools [4].

In the early days, under the policy of economic construction and development first, the government mainly invested in vocational education, which changed the proportion between the numbers of students in general high schools and those in vocational high schools from 6:4 to 3:7 [5]. Starting in 2001, the government began to adjust these proportions to help lay a foundation for a fundamental 12-year education program; subsequently, by the second half of 2010, a total of 335 general high schools and 156 vocational high schools were in existence [6]. Hung, Chiu-Shen pointed out in the Study of Senior High School Student Recruitment Marketing Communication Strategy that in recent years, the multiple enrollment program of general vocational high schools and the policy of general and vocational high schools settling in communities promoted by the government, as well as changes in the social environment have affected junior high school graduates' choice of schools [7] .

To sum up, while the preparatory measures of the 12-year fundamental education program have been in place for over ten years, how much teachers know about those educational policies that affect the school choice of the graduates of junior high schools remains uncertain. As the 12-year fundamental education program reform will soon be implemented, general and vocational high schools will face greater difficulty regarding student recruitment. If general and vocational high schools make good use of the educational reform and transformation, improvements in their current software and hardware teaching resources can be achieved through high quality and homogenous educational expenditure; these measures enhance the overall 
school quality and the comprehensive improvement of school affairs, teachers and students. The "homogenization implementation plan of general and vocational high schools' adaptive learning community educational resources" offers general and vocational high schools a greater chance of vertically cooperating with junior high schools. The "academic trial" and "vocational trial" courses will enhance the understanding that junior high school students have of community vocational high schools; this can also achieve the student recruitment target more easily due to enrollment homogenization in nearby schools [8]. The teachers' perception of the relationship between educational reform and schools' student recruitment strategy is worth a deep exploration, which is the second motive.

To realize sustainable operation, schools must adopt an education-marketing- dominated student recruitment strategy to attract students. Education-marketing dominance not only involves holding various student recruitment activities, but also incorporating educational reform into the student recruitment strategy according to the characteristics of students, with the education marketing concept as the focus of student recruitment [9]. In the presence of an increasingly competitive society, schools must rethink the management principle and direction, and adjust the management strategy according to the social trend and the trend of the times; if they still stick to the traditional management mode, they will be weeded out by the changes in the broad environment [10]. Teachers are in the front line in education activities; therefore, the success or failure of either educational reform or student recruitment of schools depends on their positive participation. The third objective is to determine vocational teachers' perception of the effects of the preparatory measures that have been implemented for many years on increasing student recruitment.

\section{Study ObJective}

Based on the above background and motive, the objectives of this study are:

1) To explore the perception of vocational teachers in general and vocational high schools of the effects of the preparatory measures of the 12-year fundamental education program on increasing student recruitment.

2) To examine the differences in the perceptions of vocational teachers, with different background variables, in general and vocational high schools in central Taiwan on the effects of the preparatory measures of the 12-year fundamental education program on increasing student recruitment.

\section{STUDY DESIGN AND IMPLEMENTATION}

\section{A. Methods and Procedures}

To achieve the above research purpose, the following research methods and procedures are constructed:

\section{1) Methods}

Data were collected from relevant literatures, research studies, compilation and analyses of relevant preparatory measures of the 12-year fundamental education program, in-depth exploration of the preparatory measures that have been implemented for many years and student recruitment related topics. Through literature arrangement, exploration and data collection via survey research, the "questionnaire of the perceptions of vocational teachers in general and vocational high schools of the effects of the preparatory measures of the 12-year fundamental education program on increasing student recruitment" was constructed. Vocational teachers from vocational high schools in central Taiwan were chosen as the population and a questionnaire survey was performed by stratified random sampling. Formal questionnaires were recovered, invalid responses were screened out, valid responses were numbered and registered, and SPSS 12.0 statistical software was used for frequency distribution, percentage, mean value, standard deviation, t-test and One Way ANOVA to make conclusions and put forth suggestions.

\section{2) Research procedure}

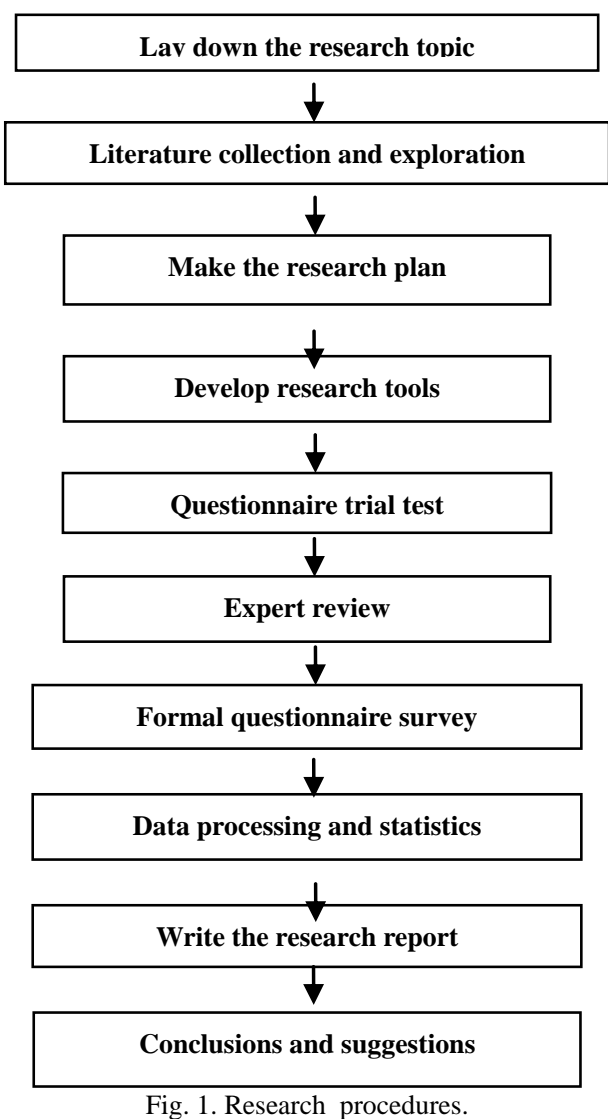

To achieve the research purpose, the research is implemented according to the following procedures (see Fig. 1)

\section{B. Research Framework}

Based on the results of the inductive analysis through an exploration of domestic and foreign relevant theories and literature, various schools draw up the relevant factors in the recruitment strategies in response to the perception of vocational teachers in general and vocational high schools on the effects of the 12-year fundamental education program on increasing student recruitment, and integrate the relationships among variables. To achieve the study objective, in the research framework, research variables are divided into independent variables (including teachers' background, 
school environment) and dependent variables (including perception of increasing student recruitment). Teacher background variables include gender, age, education, length of service, subject, position, marital status, school affiliation and school size; dependent variables refer to the perception of the effects on increasing student recruitment, including "teaching quality optimization and homogenization", "enrollment homogenization in nearby schools", "adaptive open admission", "tuition-free admission", "school admission coping strategy", etc.

\section{Research Subject}

The research is mainly targeted at vocational teachers from vocational departments attached to both senior high schools and vocational high schools in central Taiwan in 2012, and implemented in two steps: trial test questionnaire and formal questionnaire. 1) Trial test questionnaire target: after a validity review by experts, a total of 125 trial test questionnaires were issued to the vocational teachers of five schools chosen from the mother group from Mar. 20th to Apr 20,2012 ; 2) Formal questionnaire target: to reduce the research error, a total of 691 questionnaires were issued to vocational teachers from 49 vocational departments affiliated with senior high schools and vocational high schools in central Taiwan (Taichung City, Nanto County, Changhua County, etc.) selected by the stratified random sampling method during formal sampling and 568 recovered, with samples distributed evenly among the secondary schools in central Taiwan.

\section{Research Tool}

The "questionnaire on the perceptions of vocational teachers in general and vocational high schools of the effects of the preparatory measures of the 12-year fundamental education program on increasing student recruitment" was constructed as the research tool through collecting and compiling relevant literature. The questionnaire is divided into two parts: the first part is personal information, including teacher background variable (gender, age, education, length of service, subject, position and marital status) and school environment variable (school nature and school size); the second part is the "questionnaire on the perception of the effects on increasing student recruitment", covering the following five factors: "teaching quality optimization and homogenization", "enrollment homogenization nearby schools", "adaptive open admission", "tuition-free admission" and "school admission coping strategy", with a total of 47 questions.

\section{E. Content Validity}

Six scholars and experts in the technical and vocational education field and higher vocational school teacher representatives were invited to give advice about the applicability of the questions of the questionnaire, as well as the wording, to establish the content validity of the research tool and to act as an important reference for formal questionnaire revision. The formal questionnaires were constructed according to the opinions given by experts and scholars.

\section{F. Trial Test and Result Analysis}

After the initial draft of the questionnaire had been completed, to find out the adequacy and usability of the questionnaire, a trial test was performed and trial test questionnaires were issued successively from Mar. 20, 2012. Based on purposive sampling, 125 trial test questionnaires were issued to vocational teachers from five vocational departments attached to senior high schools and vocational high schools, and 108 were recovered. Item analysis, factor analysis and reliability analysis were performed on the data collected. The internal consistency of the scale was tested with Cronbach's $\alpha$ coefficient. The $\alpha$ coefficient of the "increasing student recruitment perception questionnaire" scale is .955 and the internal consistency $\alpha$ coefficient of the five sub-scales are $.948, .892, .745, .825$ and .810 ; the $\alpha$ coefficient of the questionnaire sub-scale and scale are both above .70 , and the reliability coefficient meets scholars' opinions, by which it can be known that the internal consistency of the new questionnaire (with some questions deleted) sub-scale and scale is quite good.

\section{G. Formal Questionnaire}

The trial test questionnaire of the research was revised based on the opinions of experts and scholars; inappropriate questions were deleted after item analysis, factor analysis and reliability analysis so as to construct the formal questionnaire.

\section{DATA ANALYSIS}

Statistical analysis and discussion were according to the data collected to construct the "questionnaire on the perceptions of vocational teachers in general and vocational high schools of the effects of the preparatory measures of the 12-year fundamental education program on increasing student recruitment".

1) Analysis of the current situation of the perception of vocational teachers in general and vocational schools of the effects of the preparatory measures of the 12-year fundamental education program on increasing student recruitment

TABLE I: DESCRIPTIVE STATISTICAL ANALYSIS OF THE PERCEPTION OF THE EFFECTS OF THE PREPARATORY MEASURES ON INCREASING STUDENT RECRUITMENT

\begin{tabular}{lllll}
\hline \hline Factor & M & SD & $\begin{array}{l}\text { Score } \\
\text { ranking }\end{array}$ & Effect \\
\hline $\begin{array}{l}\text { Tuition-free } \\
\text { admission }\end{array}$ & 4.14 & .62 & 1 & Excellent \\
\hline $\begin{array}{l}\text { School admission } \\
\text { coping strategy }\end{array}$ & 3.99 & .65 & 2 & Good \\
\hline $\begin{array}{l}\text { Teaching quality } \\
\text { optimization and } \\
\text { homogenization }\end{array}$ & 3.83 & .64 & 3 & Good \\
\hline $\begin{array}{l}\text { Scheme admission } \\
\text { strategy }\end{array}$ & 3.81 & .75 & 4 & Good \\
\hline $\begin{array}{l}\text { Adaptive open } \\
\text { admission }\end{array}$ & 3.64 & .77 & 5 & Good \\
\hline Overall & 3.84 & .58 & & \\
\hline \hline \begin{tabular}{l}
$N=568$ \\
\hline
\end{tabular} & & & & \\
\hline
\end{tabular}

The average scores of the perception of vocational teachers in general and vocational high schools on the effects of the preparatory measures on increasing student 
recruitment on all factors range between 3 and 4 points, showing that the teachers think the effects of the preparatory measures on increasing student recruitment is positive. The score of each factor ranks from high to low as follows: "tuition-free admission", "school admission coping strategy", "teaching quality optimization and homogenization", "scheme admission strategy" and "adaptive open admission", with an average score of 3.84. The teachers think that "tuition-free admission" increases student recruitment the most and "adaptive open admission" increases student recruitment the least (see Table I)

2) Relation between teacher background and the perception of effect on increasing student recruitment.

The differences between vocational high school teachers' perception of the effects of the preparatory measures of the 12-year fundamental education program on increasing student recruitment due to teacher background variables are shown in Table II:

TABLE II: COMPREHENSIVE ANALYSIS OF THE DIFFERENCES IN TEACHERS' PERCEPTION OF THE EFFECT ON INCREASING STUDENT RECRUITMENT DUE TO TEACHER BACKGROUND VARIABLES

\begin{tabular}{lllllll}
\hline \hline Factor & (A) & (C) & (D) & (E) & (F) & (G) \\
\hline
\end{tabular}

(I)
(II)
(2) $>(1) \quad(1)>(2)$
(2) $>(1)$

(III)

(2) $>(1)$

(IV)

(2) $>(1)$

\begin{tabular}{|c|c|c|}
\hline (V) & $(2)>(4)$ & $(2)>(1)$ \\
\hline (VI) & $(2)>(4)$ & $(1)>(2)$ \\
\hline
\end{tabular}

$N=568$

(I)Teaching quality optimization and homogenization

(II)Adaptive open admission

(III)Tuition-free admission

(IV)Scheme admission strategy

(V)School admission strategy

(VI)Overall

(A)Gender: (1) male; (2) female

(B)Age: (1) less than 30 years old; (2) 31-40 years old; (3) 41-50 years old; (4) over 51 years old

(C)Education: (1) bachelor; (2) master or $\mathrm{PhD}$ (including 40-credit-point class)

(D)Length of service: (1) less than 5 years; (2) 6-10 years; (3) 11-20 years; (4) over 21 years

(E)Subject: (1) industrial; (2) commercial; (3) housework; (4) others

(F)Position: (1) full-time teacher; (2) teacher and administrative staff (including tutors)

(G)Marital status: (1) unmarried; (2) married

- Female teachers have significantly higher perception of the effect of "adaptive open admission" on increasing student recruitment than do male teachers.

- There is no significant difference in the perception of the effect on increasing student recruitment among teachers of different ages on all factors.

- Teachers with bachelor degrees have significantly higher perception of the effect of "adaptive open admission" on increasing student recruitment that those with master/PhD degrees (including 40-credit-point class).

- Teachers with a length of service between 6 and 10 years have significantly higher perception of the effect of "school admission coping strategy" on increasing student recruitment than those with a length of service over 21 years.

- Teachers of commercial subjects have significantly higher perception of the effects of "adaptive open admission" and "scheme admission strategy" on increasing student recruitment than those of industrial subjects.

- The scores of the perception of "tuition-free admission" and "school admission coping strategy" increasing student recruitment, of teachers who are also administrative staff are higher than those of full-time teachers.

- There is no significant difference in the perception of the effect on increasing student recruitment among teachers of different marital status on all factors.

3) Relation between school environment and the perception of the effect on increasing student recruitment

The analysis results of the differences in the perception of vocational teachers in general and vocational high schools on the effect of the preparatory measures of the 12-year fundamental education program on increasing student recruitment due to different school environment variables are shown in Table III:

- Teachers of private schools have significantly higher perception of the effects of "teaching quality optimization and homogenization", "adaptive open admission", "tuition-free admission", "scheme admission strategy", and "school admission strategy" on increasing student recruitment than those of public schools.

- Teachers from schools of over 71 classes have a significantly higher perception of the effects of "teaching quality optimization and homogenization", "adaptive open admission", "tuition-free admission", and "scheme admission strategy" on increasing student recruitment than those from schools of 51-70 classes or schools of below 50 classes.

TABLE Ш: COMPREHENSIVE ANALYSIS OF THE DIFFERENCES IN TEACHERS' PERCEPTION OF THE EFFECT ON INCREASING STUDENT RECRUITMENT DUE TO SCHOOL ENVIRONMENT VARIABLES

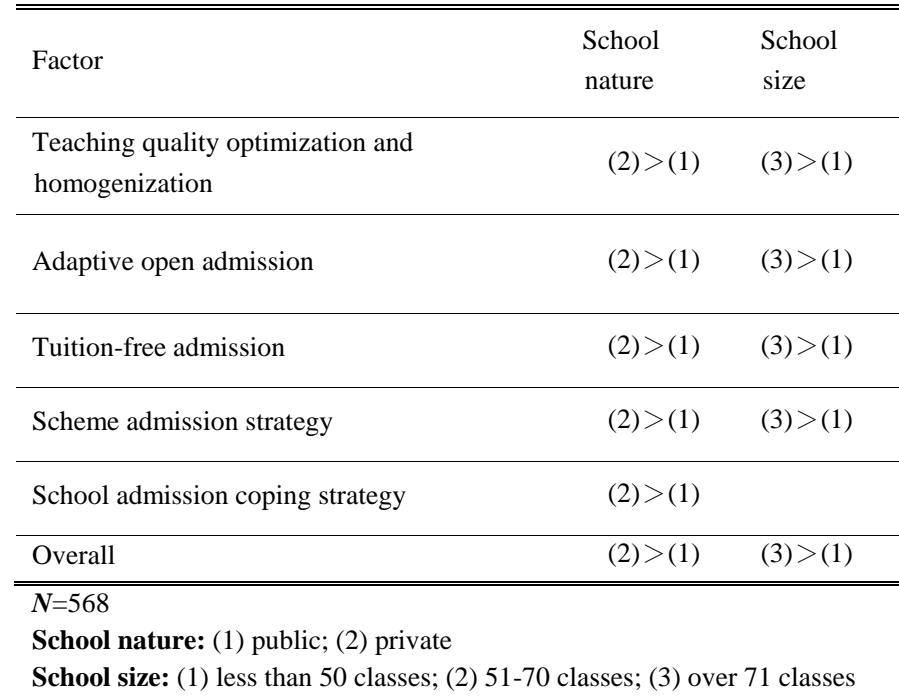




\section{CONCLUSION AND SUGgestion}

\section{A. Conclusion}

1) Analysis of the current situation of the perception of vocational teachers in general and vocational high schools of the effects of the preparatory measures on increasing student recruitment

The results in the "Scale of Vocational Teachers' Perception of the Effects of the Preparatory Measures of the 12-year Fundamental Education Program on Increasing Student Recruitment" show that vocational high school teachers think that the preparatory measures have a positive influence on student recruitment, meaning high recognition of the effects of the preparatory measures on increasing student recruitment. The average score of "tuition-free admission" (4.14 points) is the highest and that of "adaptive open admission" (3.64 points) is the lowest, showing that vocational teachers think the tuition- free policy can increase student recruitment the most among the four preparatory measures because it can ease the economic burden of parents and safeguard the educational access of children from vulnerable families.

2) Female teachers of commercial subjects with bachelor's degrees, 6-10 years of service and administrative responsibility (including tutor) have higher perception of the effects of the preparatory measures on increasing student recruitment

Among the background variables, "education" and "marital status" have no significant influence on the perception of the effect on increasing student recruitment. The background variables that have significant influence on the perception of increasing student recruitment include: gender, education, length of service, subject and position. Female teachers of commercial subjects with bachelor's degrees, 6-10-years of service and administrative responsibility (including tutor) have a higher perception of the effect of "adaptive open admission" on increasing student recruitment, but there is no significant difference in the perception of the effects on increasing student recruitment as a whole. It is presumed that those who are both teachers and administrative staff are more exposed to government policies and schools' promotional activities compared with full-time teachers, and therefore have higher recognition.

3) Teachers of public schools with over 71 classes have higher recognition of the effects of the preparatory measures on increasing student recruitment

There are significant differences in the perception of vocational teachers from schools of different "school nature" and "school size" of the effects on increasing student recruitment at all five factors, which means there are differences in the perception of vocational teachers from schools with different school environment variables on the effects of the preparatory measures on increasing student recruitment. On this basis, it can be concluded that: as vocational teachers are from schools of different environment variables and different schools pay different attention to government policy promotion and student recruitment marketing strategy, their perception of the effects of the preparatory measures on increasing student recruitment differ. Teachers from private schools have higher recognition of all factors compared with those from public schools, i.e. student recruitment is the most important continuous work all year round in private schools. The government's educational guideline and policy is the most important factor for students and parents in choosing schools. To achieve sustainable operation, private schools attach great importance to student recruitment marketing, so teachers from private schools have higher recognition of the effect on increasing student recruitment compared with those from public schools. In contrast, teachers from schools with over 71 classes have higher perception of the effect on increasing student recruitment compared with those from schools with below 50 classes, showing that there are significant differences in school history, school reputation and administrative efficiency between large and small schools, so teachers from the former have higher recognition.

\section{B. Suggestions}

\section{1) For education competent authorities}

Strengthen the 12-year fundamental education program: research results indicate that some teachers are not fully aware of the preparatory measures that have been implemented for many years nor of the influence these measures have had, so it is suggested that the competent education authorities should strengthen the promotion of the plan among public school teachers, as well as target and develop other educational trends in the future. The teachers' perception of "adaptive open admission" is the weakest, and most teachers have a poor perception of open admission, admission method, school district division, special student recruitment and relevant measures. Authorities should clarify the admission method of the 12-year fundamental education program, enhance teachers' understanding of the admission method for future secondary education and allow more time for teachers and school units to prepare for post-transformation education.

\section{2) For schools and teachers}

Grasping education reform to improve schools' education quality: the research results show that vocational teachers think the tuition-free policy makes private schools more competitive in student recruitment, so injecting more educational funding could improve software and hardware equipment, thereby enhancing their competitiveness. It is suggested that private schools make good use of the educational reform to gradually enhance their overall education quality through the optimization and homogenization plan and strengthen schools' software and hardware equipment via education expenditure, and obtain the support of their teachers so as to be more competitive in student recruitment. As for public schools, it is suggested, that besides improving education quality through a program of optimization and homogenization, to achieve sustainable operation, they should be reviewed and have education reform incorporated into their student recruitment marketing strategy. As for teachers, their knowledge about the concepts of school operation need to be strengthened to keep pace with the times, and their attitude towards lifelong learning needs to be supported so that they may rise to the challenge of multi-information and the rapid changes in society and reforms in education. 


\section{REFERENCES}

[1] DOS of MOE, Senior Secondary Education Student Number Forecast Analysis Report (100 110 school year), Taipei: Ministry of Education, 2011, pp. 112-138.

[2] C. L. Wang. (Aug. 16, 2011). Private general and vocational high schools may close down one after another ten years from now due to low birth rate. [Online]. Available: http://mag.udn.com/mag/campus/storypage.jsp?f_MAIN_ID=13\&f_S UB_ID=104\&f_ART_ID=336943.

[3] MOE, 12-year Fundamental Education Implementation Plan, Taipei: Ministry of Education, 2011, pp. 45-63.

[4] C. S. Yung, "The aftermath of 12-year compulsory education: secondary education at the crossroad," Educational Material Collection, vol. 46, pp. 1-26, 2010.

[5] S. H. Lin, The Relationship between School Marketing and Enrollment Performance - Evidence from Senior High Schools in Central Taiwan, M.S. thesis, Department of Technology Management, Chung Hua University. 2006, PP.18-33.

[6] MOE, Guidelines for the Ministry of Education to Subsidize the First Three Years' Tuition for Students of the Senior Secondary Schools and the Five-year Junior Colleges, Taipei: Ministry of Education, 2011, pp. 33-58.

[7] C. S. Hung, A Study on Marketing Communication Strategies for Senior High School Enrollment in Taiwans, Ph.D. dissertation, Institute of Business Administration, Taichung Health and Management Institute, 2005, pp. 48-65.

[8] MOE, The various promotional works deployed by the MOE for 12-year Fundamental Education Implementation Plan approved the Executive Yuan, Taipei: Ministry of Education, 2011, pp. 13-29.

[9] Y. C. Yang, A Study on the Student Recruitment Promotion Models of Taipei Municipal Senior, M.S. thesis, Institute of Technological and Vocational Education, National Taipei University of Technology, 2004, pp. 49-63.

[10] Q. S. Wu, "School innovative management principle and strategy," Teachers' World, vol. 128, pp. 30-44, 2004.

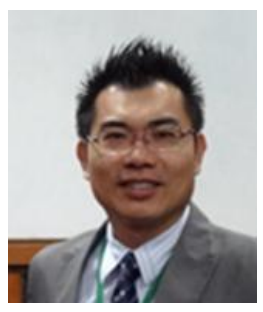

Tsai-Ku Liao received M.S. degree at the Department of Geography from National Taiwan Normal University in 2006, and currently he is a doctoral student of the Department of Industrial Education and Technology at National Changhua University of Education (NCUE), Taiwan, R.O.C. Since August 2008, he has been a director of Student Affairs and Library in National Taichung First Senior High School (TCFSH) in Taiwan, R.O.C. Since August 1998, he has taught courses in Geogrpahy , GIS , Monographic study in the same school.

Tsai-Ku Liao received M.S. degree at the Department of Geography from National Taiwan Normal University in 2006, and currently is a doctoral student of the Department of Industrial Education and Technology at National Changhua University of Education (NCUE), Taiwan, R.O.C. Since August 2008 , he has been a director of Student Affairs and Library in National Taichung First Senior High School(TCFSH) in Taiwan, R.O.C. Since August 1998, he has taught courses in Geogrpahy , GIS , Monographic study in the same school.

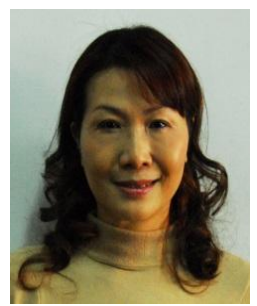

Hui-Yi Pai is dedicating her life in fine arts, is pursuing her Ph.D. in Natioanl Changhua University of Education.

She has had eight solo exhibitions all over the world including the recent one in Vancouver, Canada and a publication: Flash Back. Ms. Pai is the recipient of several awards such as French Art Salon collection award, International Japan FIA Art Exibition a ward, Taiwan Art Exhibition collection award, YuShan Art Exhibition collection award, Tai-Yang Art Exhibition award, Da Dung Fine Arts Exhibition award, Central Taiwan Art Exhibition award and Tea Township Thousand people outdoor sketching.

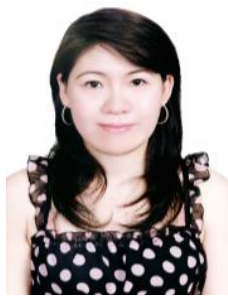

Yi-Chen Chang received M.S. in Graduate Institute of Technology and Vocational Education National Taipei University of Technology in 2009, and is studying Ph.D. in Department of Industrial Education and Technology at National Changhua University of Education (NCUE) in Taiwan, R.O.C. respectively. Since August 2008, she served the position as the director in Department of Fashion and Styling Design at Chungyu Institute of Technology in Taiwan, R.O.C. She is the director of Department of Fashion and Styling Design at Yuda University of Science and Technology from 2011 until now. She teaches courses in hairdressing and cosmetology. Her research interest is technology and vocational education.

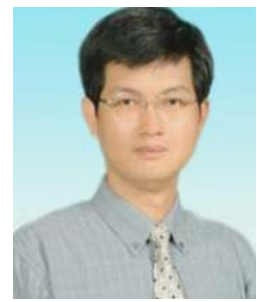

Chin-Wen Liao received both M.S. and Ph.D. in Industrial Education from National Taiwan Normal University, Taiwan, R.O.C. in 1994 and 2002, respectively. Since August 2011, he has been a professor in Department of Industrial Education and Technology at National Changhua University of Education (NCUE) in Taiwan, R.O.C. At the same time. He teaches courses in technology and vocational education, energy education, teacher education, course and teaching, organization learning. His research interests include technology and vocational education, energy education of technology, automatic control, and knowledge management. 